\title{
Storage Application in Smart Grid with High PV and EV Penetration
}

\author{
Hashemi Toghroljerdi, Seyedmostafa; Yang, Guangya; Østergaard, Jacob; You, Shi; Cha, Seung-Tae
}

Published in:

Proceedings of IEEE Innovative Smart Grid Technologies Europe 2013

Link to article, DOI:

10.1109/ISGTEurope.2013.6695447

Publication date:

2013

Link back to DTU Orbit

Citation (APA):

Hashemi Toghroljerdi, S., Yang, G., Østergaard, J., You, S., \& Cha, S-T. (2013). Storage Application in Smart Grid with High PV and EV Penetration. In Proceedings of IEEE Innovative Smart Grid Technologies Europe 2013 IEEE. https://doi.org/10.1109/ISGTEurope.2013.6695447

\section{General rights}

Copyright and moral rights for the publications made accessible in the public portal are retained by the authors and/or other copyright owners and it is a condition of accessing publications that users recognise and abide by the legal requirements associated with these rights.

- Users may download and print one copy of any publication from the public portal for the purpose of private study or research

- You may not further distribute the material or use it for any profit-making activity or commercial gain

- You may freely distribute the URL identifying the publication in the public portal 


\title{
Storage Application in Smart Grid with High PV and EV Penetration
}

\author{
Seyedmostafa Hashemi, Student Member, IEEE, Guangya Yang, Member, IEEE, Jacob Østergaard, Senior Member, \\ IEEE, Shi You, and Seung-Tae Cha. \\ Center for Electric Power and Energy, Department of Electrical Engineering \\ Technical University of Denmark \\ 2800 Kgs. Lyngby, Denmark \\ \{shtog, gyy, joe, sy, stc\}@elektro.dtu.dk
}

\begin{abstract}
Rapid deployment of renewable energy sources (RES) and concerns regarding their impacts on power systems provide new opportunities for utilizing more electrical energy storage system (EESS) in power systems. Peak-shaving in high Photovoltaic (PV) penetration conditions and providing ancillary service in high load conditions are among the applications of EESS in distribution systems. In this paper, a new method is developed based on the voltage sensitivity analysis of the network in order to calculate the EESS capacity required for prevention of voltage rise and voltage drop in distribution grids with residential PVs and Electric Vehicles (EVs). The effect of EV home charging on EESS capacity in high $P V$ penetration is also addressed. The results indicate that increasing the EV penetration in the network can decrease the EESS capacity need. This decrease is highest in situations with low $P V$ penetration.
\end{abstract}

Index Terms-- Energy storage, smart grid, photovoltaic, electric vehicle.

\section{INTRODUCTION}

Photovoltaics (PV) are amongst the most rapid growth renewable energy technologies worldwide. The annual growth rate of these systems has been more than $44 \%$ in the last decade and the installed capacity of them has increased from $1000 \mathrm{MW}$ in 2000 to $18.2 \mathrm{GW}$ at the end of 2010 [1]. Trends show that in the future, the majority of new PV installations will be grid-connected residential PVs [2]-[3] whose capacity is normally less than $10 \mathrm{~kW}$ and are connected to low voltage (LV) distribution systems [4].

The distribution systems were traditionally designed to operate in radial configuration and the power flow direction was considered as mono-directional from the upstream network toward the loads. By increasing the PV penetration in residential areas, concerns regarding the reverse power flow are growing. One of the main problems with reverse power flow is the voltage rise at the point of common coupling (PCC) and neighbor buses [5]-[10]. The severity of this impact varies according to the PV size and location, and also the network configuration to which PV is connected [2], [4], [11]. On the other hand, with the increasing adoption of EVs, the distribution systems are involved in transportation and the

This work was supported in part by PVNET.dk project sponsored by Energinet.dk under the Electrical Energy Research Program (ForskEL, grant number 10698). existing grids need to satisfy these new growing loads which mean new challenges for DNOs [12]-[14]. In fact, in a welldesigned distribution system, the voltage drop is limited to a special amount in the full load condition according to related standards. However, in many cases, the EV loads are not considered in distribution system design and the voltage drop may occur at some weak points in high load conditions. It may be concluded that by aggregation of EV and PV in the network, both the voltage drop and the voltage rise issues can be solved. However, the voltage drop usually happens at the time when there is low or no PV generation; therefore, both voltage rise and drop may happen in residential areas with high PV and EV penetration.

In recent years, electrical energy storage systems (EESS) have been heeded by both researchers and system operators as an effective solution for overcoming the challenges associated with PV technologies [15]. EESS can be used to prevent overvoltage, smooth the fluctuation of the PV output, or trade power under time-of-use electricity pricing in the PV applications [16]. In addition, by using EESS in the network, the voltage drop problem caused by EV home charging can be solved by transferring the stored energy during high PV generation and low load periods to the low or no PV and high load consumption periods.

In this paper, a method is developed based on the voltage sensitivity analysis of the network in order to calculate the EESS capacity which is required to prevent the voltage rise and drop in distribution grids. The method is capable of evaluating the effects of EV home charging on storage capacity needed in LV grids with high residential PV prevention. Different scenarios for both PV and EV penetration are simulated. The structure of the paper is as follows: the voltage quality issues caused by high PV and EV penetration are described in section II, the energy storage application for voltage control in smart grid is explained in section III, the proposed method is illustrated in section IV, and simulation results are shown in the last section.

\section{Voltage QUALITy IsSUES CAUSED BY HIGH PV AND EV PENETRATION}

Voltage rise at the point of common coupling (PCC) is a well-known issue associated with active power feed-in by PV units. To emphasize, consider the thevenin equivalent of a typical PV system connected to an LV grid as shown in Fig.1. 


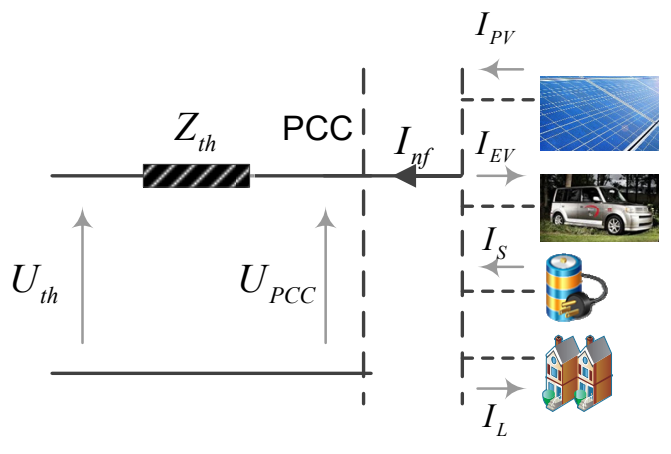

Figure 1. Thevenin equivalent of a typical PV system connected to the grid

In this figure, the $\underline{Z}_{t h}$ and $\underline{U}_{t h}$ are the thevenin impedance and the thevenin voltage, respectively, $\underline{I}_{P V}$ is feed-in current of $\mathrm{PV}, \underline{I}_{S}$ is the storage current, $\underline{I}_{E V}$ is the EV charging current, and $\underline{I}_{L}$ models the local consumption, all in per-unit. The local voltage, $\underline{U}_{P C C}$, is determined by $\underline{U}_{t}$, the local generation and also the local consumption. To simplify, suppose that $\underline{U}_{t h}$ is fixed at 1 p.u. with a power angle of $0^{\circ}$. The net feed-in current can be calculated by:

$$
\underline{I}_{n f}=\underline{I}_{P V}-\underline{I}_{L}-\underline{I}_{E V} \pm \underline{I}_{S}=\left(\frac{\underline{S}_{n f}}{\underline{U}_{P C C}}\right)^{*}
$$

where $\underline{S}_{n f}$ is the net apparent power injected into the grid. By considering the active and reactive power and neglecting the power loss across the thevenin impedance, the $\underline{I}_{n f}$ can be rewritten as:

$$
\underline{I}_{n f}=\left(\frac{P-j Q}{\underline{U}_{t h}}\right)=P-j Q
$$

The voltage at PCC can be calculated as:

$$
\underline{U}_{P C C}=\underline{U}_{t h}+\underline{Z}_{t h} \times \underline{I}_{n f}
$$

Suppose that $\underline{Z}_{t h}=R_{t h}+j X_{t h}$. Thus:

$$
\begin{aligned}
\underline{U}_{P C C}=\left(1+P \times R_{t h}+\right. & \left.Q \times X_{t h}\right)+ \\
& j\left(P \times X_{t h}-Q \times R_{t h}\right)
\end{aligned}
$$

According to some current standards, the voltage control by reactive power control capability of PV inverters is not allowed [17]. In addition, the load power factor for household application is near one; therefore, the reactive power can be neglected and the magnitude of $\underline{U}_{P C C}$ can be calculated as in the following:

$$
\left|\underline{U}_{P c c}\right|=\sqrt{\left(1+P \times R_{t h}\right)^{2}+\left(P \times X_{t h}\right)^{2}}
$$

In many LV grids, the $\mathrm{R} / \mathrm{X}$ ratio is high [18]; therefore, with a good approximation, the magnitude of the voltage at the connection point can be summarized as follows:

$$
\left|\underline{U}_{P c c}\right|=\left|1+P \times R_{t h}\right|
$$

According to the standards applied to LV grids, the voltage rise and drop at the connection point should be limited to a special amount; therefore:

$$
V_{\min } \prec\left|1+P \times R_{t h}\right| \prec V_{\max }
$$

$V_{\min }$ and $V_{\max }$ are the maximum and minimum allowed voltages in LV grids, respectively. Without considering the EESS, the variable $P$ can be calculated as follows:

$$
P(\mathrm{t})=P_{P V}(\mathrm{t})-P_{A L}(\mathrm{t})
$$

where $P_{A L}$ is aggregated load and EV consumption and $P_{P V}$ is PV generation. During the periods when the PV generation is high and at the same time, the local consumption is low, $P$ is positive. This condition may specifically happen at noontime. On the other hand, $P$ is negative when there is high consumption and low or no PV generation. The maximum power that can be injected into the grid by PV without overvoltage occurrence and the maximum load consumption without voltage drop occurrence can be calculated as follows:

$$
\left\{\begin{array}{l}
\left|P_{P V, \text { max }}(\mathrm{t})\right|=\left|P_{A L}(\mathrm{t})\right|+\frac{V_{\text {max }}-1}{R_{\text {th }}} \\
\left|P_{A L, \text { max }}(\mathrm{t})\right|=\left|P_{P V}(\mathrm{t})\right|+\frac{1-V_{\text {min }}}{R_{\text {th }}}
\end{array}\right.
$$

According to the previous equations, the $P_{P V}$ and $P_{A L}$ have to be limited to $P_{P V, \max }$ and $P_{A L, \max }$, respectively for prevention of voltage rise and voltage drop in the network.

\section{ENERGY STORAGE APPLICATION FOR VOLTAGE CONTROL IN SMART GRID}

EESS can be used in Smart grids as an effective tool for overcoming the challenges associated with PV generation. Not only is EESS an effective energy management tool, but also it can participate in active power management by injecting and absorbing active power in order to improve power quality of the grid. In other words, EESS can be used as a reliable distributed energy resource (DER) in the network. Customers with EESS are usually anticipated to have smoother and predictable load profiles; therefore, more efficient planning and operation can be carried out by DNOs; also new investment for upgrading the current system can be minimized [19]. In this part, two main applications of EESS for voltage control in smart grid with high PV and EV penetration are investigated.

\section{A. Peak-shaving functionality of EESS}

As discussed before, the severity effects of PV on the grid voltage mainly depends on PV size and location, grid configuration, and load condition. Installation of PV in locations that have high load consumption during daylight hours can minimize the problems associated with high PV penetration. However, in residential areas, where the peak consumption occurs in the evening, the load consumption during high PV generation periods is relatively low. As a result, the effects of PV installation in residential areas can be considered as one of the worst-case scenarios regarding PV installation.

Increasing the PV hosting capacity of LV grids can be considered as one of the main applications of EESS in high PV penetration condition [19]. To prevent the overvoltage in residential areas, which is among the main power quality 
issues associated with high PV penetration, EESS can be used as a peak-shaving tool. To this aim, the output power of PV can be limited to a special amount by storing the exceeded energy, and this stored energy can be used in other hours with higher load consumption or electricity price. It should be noted that curtailing the active power at lower levels results in higher EESS capacity and vice versa.

\section{B. Ancillary service by using EESS}

With the increasing adoption of EVs, the distribution systems are involved in transportation and the existing grids need to satisfy these new growing loads [12]-[14]. Based on the EV penetration, the residential load profile may change and in some grids, the grid reinforcement is necessary [14] Even in LV grids with high PV penetration, the voltage drop may happen, because the PVs do not produce much power during evening hours. However, in smart grids equipped with EESS, a part of energy consumption can locally be supplied by EESS. In fact, EESS can be used as both DER and controllable load in smart grid applications [19]. A schematic of EESS application in high PV and EV penetration is shown in Fig. 2. Both peak-shaving and ancillary service functionality of EESS are shown in this figure. As can be seen, a part of active power generated by PV can be stored in EESS during noontime and be used during peak-load periods.

\section{METHOD DESCRIPTION}

PV penetration can be defined in different ways such as total installed PV capacity being compared with the peak-load demand [3], total PV generation to total generation [2], total PV power to total system real power of all nominal loads [12], etc. As the focus of this paper is on residential areas, the PV penetration is defined as follows:

$$
P V P=\frac{\text { The number of customers with PV system }}{\text { Total number of customers }}
$$

In the same way, the EV penetration is defined based on the number of customers with $\mathrm{EV}$, as follows:

$$
E V P=\frac{\text { The number of customers with EV }}{\text { Total number of customers }}
$$

In this paper, we used the sensitivity analysis as an effective tool which requires less computational time than load flow calculations. The Jacobian matrix is used here, which is derived from power flow equations related to NewtonRaphson (NR) load-flow solution. To emphasize, consider an $\mathrm{N}$-bus power system. By using the power-flow equations, the following set of linear equations can be written:

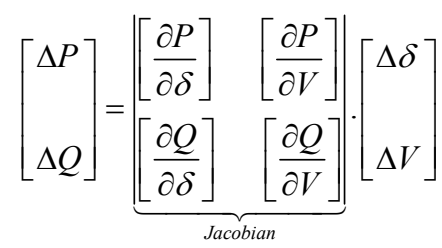

where $P, Q, V$ and $\delta$ are the injected active power into the grid, injected reactive power into the grid, magnitude of bus voltage phasor, and angle of bus voltage phasor, respectively.

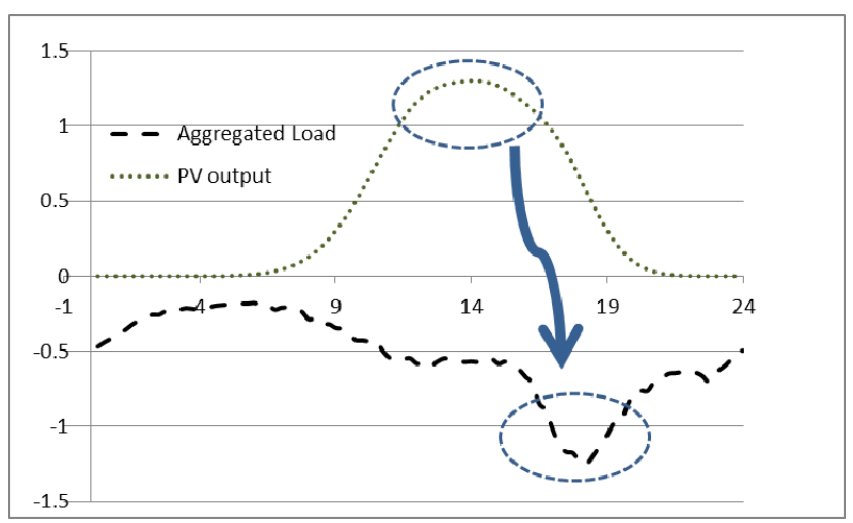

Figure 2. A schematic of EESS application in high PV and EV penetration conditions

Now, suppose that the load power factor is near one and reactive power control by $\mathrm{PV}$ inverter is not permitted; therefore, we can suppose that $Q \approx 0$. By solving the previous equation, the voltage sensitivity matrix can be extracted as in the following:

$$
\left[\begin{array}{c}
\Delta \delta \\
\Delta V
\end{array}\right]=\left[\begin{array}{l}
S_{\delta P} \\
S_{V P}
\end{array}\right] \times \Delta P
$$

Provided that the Jacobian is well-conditioned, the bus voltage can be calculated as in the following:

$$
\left[\begin{array}{c}
V_{2} \\
\ldots \\
V_{n}
\end{array}\right]=V_{S}+\left[\begin{array}{ccc}
S_{V P 2,2} & \ldots & S_{V P, n} \\
\ldots & \ldots & \ldots \\
S_{V P n, 2} & \ldots & S_{V P n, n}
\end{array}\right] \times\left[\begin{array}{c}
\Delta P_{2} \\
\ldots \\
\Delta P_{n}
\end{array}\right]
$$

where $V_{S}$ is the voltage of the swing or slack bus.

When the local generation is more than consumption, the injected power into the grid is positive and according to the previous equation, the voltage at the PCC increases to a level higher than PCC voltage without PV generation. On the other hand, when local consumption is higher than generation, the PCC voltage drops to a voltage lower than the previous condition. Both the voltage rise and drop are functions of PV generation, load consumption, and network configuration. These can be concluded as follows:

$$
\left\{\begin{array}{l}
V_{r}(t)=f_{1}\left(S_{p}, P_{P V}(\mathrm{t}), P_{L}(\mathrm{t})\right) \\
V_{d}(t)=f_{2}\left(S_{p}, P_{P V}(\mathrm{t}), P_{L}(\mathrm{t})\right)
\end{array}\right.
$$

$P_{P V}$ and $P_{L}$ are PV generation and aggregated EV and load consumption, respectively. Now, suppose that the net injected power into the grid in bus $n$ is defined as in the following:

$$
N I P_{n}(t)=P_{P V, n}(t)-P_{L, n}(t)
$$

This power depends on both PV generation and load consumption in bus $n$ at each time. By using (11) and (13), the voltage of bus $\mathrm{n}$ can be determined as in the following: 


$$
V_{n}(t)=V_{s}(t)+\sum_{g=2}^{N}\left(S_{V P n, g} \times N I P_{n}(t)\right)
$$

To maintain the voltage of bus $n$ lower than the maximum allowed value, a special amount of EESS has to be installed in this bus to curtail the power at the specific level $P$. The required storage can be calculated as in the following:

$$
\text { Storage }_{n}^{P}=\int_{N I P_{n}(t) \succ P} N I P_{n}(t) d t
$$

On the other hand, to prevent the unaccepted voltage drop during peak load, a part of consumption should be supplied locally by means of EESS. The required storage to support the grid voltage when the load consumption in bus n exceeds $L$ can be calculated as follows:

$$
\text { Storage }_{n}^{L}=\int_{N I P_{n}(t) \prec-L}\left|N I P_{n}(t)\right| d t
$$

The minimum storage required to prevent the voltage rise and drop can be calculated by solving the following equation:

$$
\text { Minimize } \sum_{i=2}^{m} \max \left(\text { Storage }_{i}^{P}, \text { Storage }_{i}^{L}\right)
$$

S.t.

$$
\left\{\begin{array}{c}
V_{\text {min }} \prec \sum_{g=2}^{m}\left(S_{V P 2, g} \times N I P(t)\right) \prec V_{\text {max }} \\
\ldots \\
V_{\text {min }} \prec \sum_{g=2}^{m}\left(S_{V P m, g} \times N I P(t)\right) \prec V_{\text {max }}
\end{array}\right.
$$

\section{Simulation Results}

A low voltage feeder of the Danish island Bornholm with 52 customers is selected for simulations as depicted in Fig. 3. The feeder is supplied by one $100 \mathrm{kVA}, 10 / 0.4 \mathrm{kV}$ transformer. Different scenarios for both $\mathrm{PV}$ and $\mathrm{EV}$ penetration are simulated. Daily EV load profiles are based on the EV home charging concept derived from data provided by [12]. Three aggregated load and EV scenarios for $100 \%, 50 \%$, and $0 \% \mathrm{EV}$ penetration used for simulations are shown in Fig. 4 [12], [14].

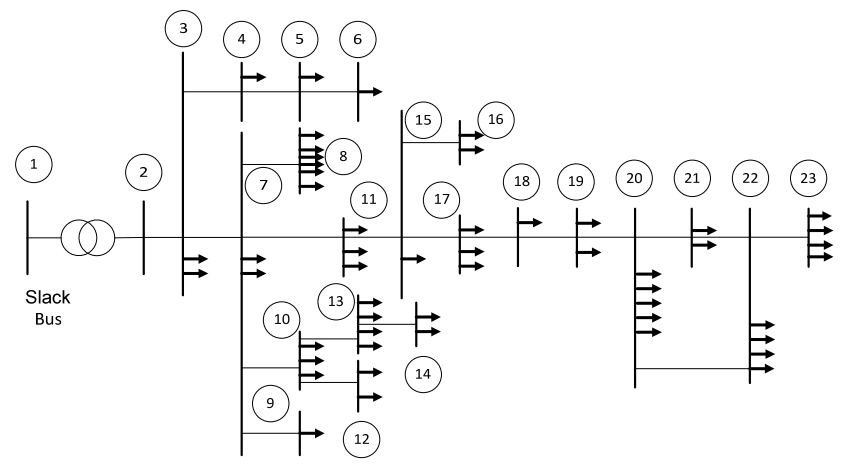

Figure 3. Single-line diagram of the LV grid used for simulations

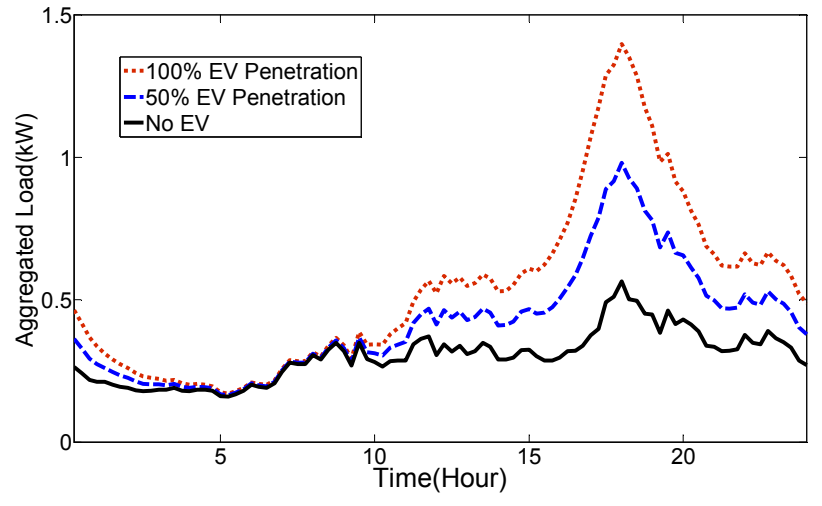

Figure 4. Aggregated load for $100 \%, 50 \%$, and $0 \% \mathrm{EV}$ penetration for home charging concept

Simulations showed that without applying EESS, the grid encountered serious voltage quality issues in high PV and EV penetration conditions. The maximum and the minimum voltages of different buses in the conditions of high PV and EV penetration are shown in Fig. 5. This figure indicates that both the voltage rise and voltage drop may happen in the network in high PV and EV penetration condition. The occurrence probability of these power quality issues is higher in locations with higher thevenin impedances. The daily voltage profile of a customer located at bus 23 is shown in Fig. 6.

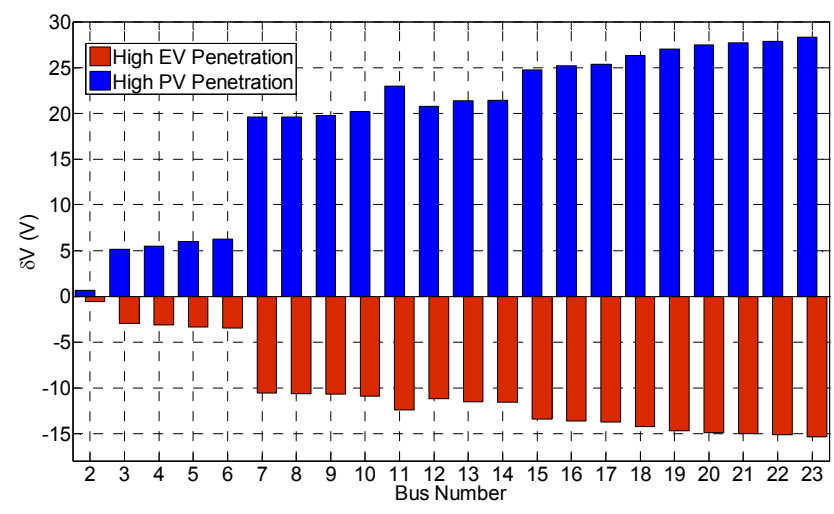

Figure 5. The maximum and the minimum voltages of different buses in the conditions of high PV and EV penetration

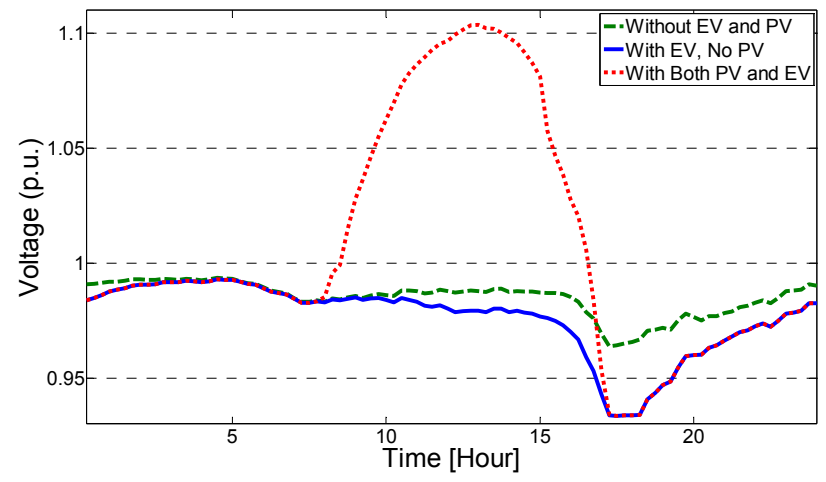

Figure 6. The daily voltage profiles of a customer located at bus 23 
The required capacity of EESS to maintain the voltage at an acceptable band in different scenarios of PV and EV penetration for some buses is shown in Table I. The simulations show that the required EESS for overvoltage prevention is different according to the location of customers. The EESS capacity is less for buses located nearer the transformer as they have less sensitivity to the active power. For example, the EESS capacity is zero in bus 3 for all simulated scenarios. Moreover, the results indicate that increasing the EV penetration in the network can decrease the EESS capacity required for overvoltage prevention in different PV penetration levels. The level of decrease in the EESS capacity in the condition of $100 \% \mathrm{PV}$ penetration is around 7 and $12 \%$ for 50 and $100 \%$ EV penetration, respectively. This decrease is more in the condition of $50 \% \mathrm{PV}$ penetration and is around 18 and $32 \%$ for 50 and $100 \%$ EV penetration, respectively. In general, the percentage of this decrease is more in lower PV penetration as shown in Fig. 7.

\section{CONCLUSION}

In this paper, a method was developed in order to calculate the EESS capacity required for voltage rise and voltage drop prevention in LV grids. The simulations indicated that without applying EESS, the grid encountered serious voltage quality issues in high $\mathrm{PV}$ and $\mathrm{EV}$ penetration conditions. The occurrence probability of these power quality issues was higher in locations with higher thevenin impedances. Moreover, the results indicated that increasing the EV penetration in the network can decrease the EESS capacity required for overvoltage prevention in different $\mathrm{PV}$ penetration levels. The percentage of this decrease was more in lower PV penetration.

TABLE I. EESS CAPACITY IN DIFFERENT CONDITIONS. EVP=EV PENETRATION, AV= AVERAGE CAPACITY PER CUSTOMER

\begin{tabular}{|c|c|c|c|c|c|c|}
\hline \multirow{2}{*}{} & \multicolumn{6}{|c|}{ EESS Capacity per Customer (kWh) } \\
\cline { 2 - 7 } & EVP & Bus3 & Bus7 & Bus17 & Bus23 & Av \\
\hline $\mathbf{1 0 0 \% ~ P V ~}$ & 0 & 0 & 6.3 & 25.8 & 35.7 & 19 \\
\cline { 2 - 7 } Penetration & 50 & 0 & 5.6 & 24.1 & 33.6 & 17.8 \\
\cline { 2 - 7 } & 100 & 0 & 5.2 & 21.9 & 31.6 & 16.6 \\
\hline $\begin{array}{c}\mathbf{7 5 \%} \text { PV } \\
\text { Penetration }\end{array}$ & 0 & 0 & 2.7 & 14.1 & 23 & 11.2 \\
\cline { 2 - 7 } & 50 & 0 & 2.5 & 11.9 & 21.1 & 10.2 \\
\cline { 2 - 7 } & 100 & 0 & 2.4 & 10.2 & 19.1 & 9.2 \\
\hline 50\% PV & 0 & 0 & 0 & 4.15 & 9.7 & 4.1 \\
\cline { 2 - 7 } Penetration & 50 & 0 & 0 & 3.4 & 7.8 & 3.3 \\
\cline { 2 - 7 } & 100 & 0 & 0 & 2.8 & 6 & 2.8 \\
\hline
\end{tabular}

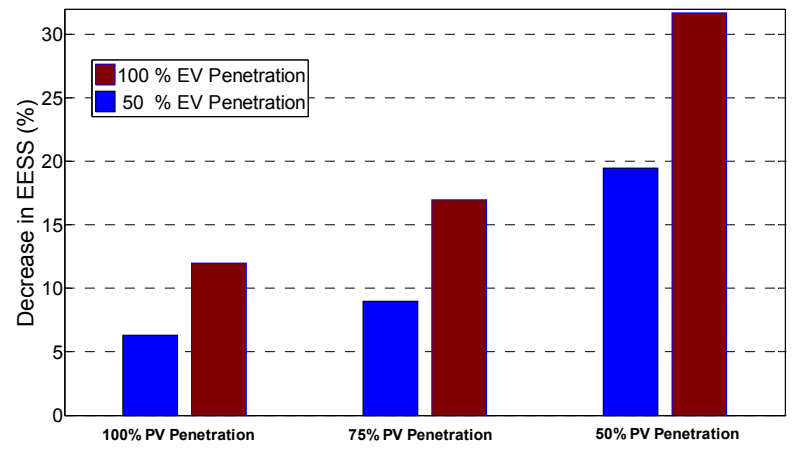

Figure 7. The percentage of decrease in EESS capacity in different PV and EV penetration

\section{REFERENCES}

[1] L. Chia-Hung, H. Wei-Lin, C. Chao-Shun, H. Cheng-Ting, and K. TeTien, "Optimization of Photovoltaic Penetration in Distribution Systems Considering Annual Duration Curve of Solar Irradiation," IEEE Trans. Power Syst., vol. 27, pp. 1090-1097, 2012.

[2] M. E. Baran, H. Hooshyar, S. Zhan, and A. Huang, "Accommodating High PV Penetration on Distribution Feeders," IEEE Trans. Smart Grid, vol. 3, pp. 1039-1046, 2012.

[3] Y. Liu, J. Bebic, B. Kroposki, J. de Bedout, and W. Ren, "Distribution System Voltage Performance Analysis for High-Penetration PV," in proc. Energy 2030 Conference, 2008, pp. 1-8.

[4] K. F. Katiraei, Agu, x, and J. R. ero, "Solar PV Integration Challenges," IEEE Power Energy Mag., vol. 9, pp. 62-71, 2011.

[5] M. E. Baran, H. Hooshyar, S. Zhan, and A. Huang, "Accommodating High PV Penetration on Distribution Feeders," IEEE Trans. Smart Grid, vol. 3, pp. 1039-1046, 2012.

[6] S. Balathandayuthapani, C. S. Edrington, S. D. Henry, and C. Jianwu, "Analysis and Control of a Photovoltaic System: Application to a HighPenetration Case Study," Systems Journal, IEEE, vol. 6, pp. 213-219, 2012.

[7] M. Thomson and D. G. Infield, "Impact of Widespread Photovoltaics Generation on Distribution Systems," IET Renewable Power Generation, vol. 1, pp. 33-40, 2007.

[8] R. A. Shayani and M. A. G. de Oliveira, "Photovoltaic Generation Penetration Limits in Radial Distribution Systems," IEEE Trans. Power Systems, vol. 26, pp. 1625-1631, 2011.

[9] Y. Ueda, K. Kurokawa, T. Tanabe, K. Kitamura, and H. Sugihara, "Analysis Results of Output Power Loss Due to the Grid Voltage Rise in Grid-Connected Photovoltaic Power Generation Systems," IEEE Trans. Industrial Electronics, vol. 55, pp. 2744-2751, 2008.

[10] R. Tonkoski, L. A. C. Lopes, and T. H. M. El-Fouly, "Coordinated Active Power Curtailment of Grid Connected PV Inverters for Overvoltage Prevention," IEEE Trans. Sustainable Energy, vol. 2, pp. 139-147, 2011.

[11] R. Tonkoski, D. Turcotte, and T. H. M. El-Fouly, "Impact of High PV Penetration on Voltage Profiles in Residential Neighborhoods," IEEE Trans. Sustainable Energy, vol. 3, pp. 518-527, 2012.

[12] A. Lojowska, D. Kurowicka, G. Papaefthymiou, and L. van der Sluis, "Stochastic Modeling of Power Demand Due to EVs Using Copula," IEEE Trans. Power Syst., vol. 27, pp. 1960-1968, 2012.

[13] A. Ashtari, E. Bibeau, S. Shahidinejad, and T. Molinski, "PEV Charging Profile Prediction and Analysis Based on Vehicle Usage Data," IEEE Trans. Smart Grid, vol. 3, pp. 341-350, 2012.

[14] L. Lan, M. Eisenreich, G. Balzer, and A. Kessler, "Impact assessment of electric vehicles on existing distribution grids with decentralized Photovoltaic Generators," in Proc. Modern Electr. Power Syst., 2010, pp. 1-6.

[15] O. M. Toledoa, D. O. Filhoa, and A. S. A. C. Dinizb, "Distributed photovoltaic generation and energy storage systems: A review," Renew. Sustain. Energy Rev., vol. 14, pp. 506-511, 2010.

[16] W. A. Omran, M. Kazerani, and M. M. A. Salama, "Investigation of methods for reduction of power fluctuations generated from large grid connected photovoltaic systems," IEEE Trans. Energy Convers., vol. 26, no. 1, pp. 318-327, 2011.

[17] Y. Ruifeng and T. K. Saha, "Voltage Variation Sensitivity Analysis for Unbalanced Distribution Networks Due to Photovoltaic Power Fluctuations," IEEE Trans. Power Systems, vol. 27, pp. 1078-1089, 2012.

[18] Y. Ruifeng and T. K. Saha, "Investigation of Voltage Stability for Residential Customers Due to High Photovoltaic Penetrations," IEEE Trans. Power Systems, vol. 27, pp. 651-662, 2012.

[19] "Connecting the Sun: Solar photovoltaics on the road to large-scale grid integration", European Photovoltaic Industry Association (EPIA), Sep. 2012, [Online]. Available: www.connectingthesun.eu. 